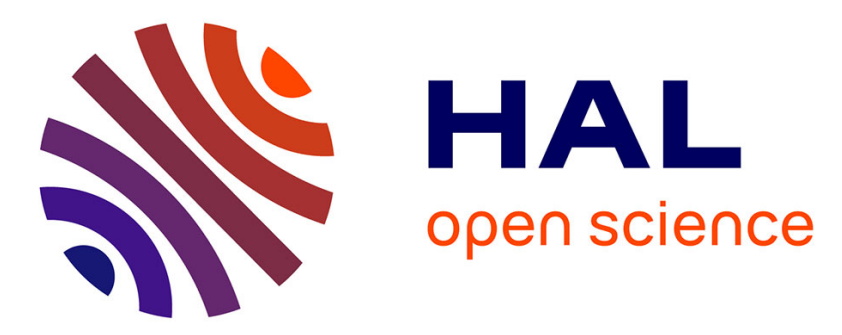

\title{
Influence of traces of oxidized polymer on the performances of bulk heterojunction solar cells
}

Anthony Perthué, Thérèse Gorisse, Hugo Santos Silva, Didier Bégué, Agnès

Rivaton, Guillaume Wantz

\section{- To cite this version:}

Anthony Perthué, Thérèse Gorisse, Hugo Santos Silva, Didier Bégué, Agnès Rivaton, et al.. Influence of traces of oxidized polymer on the performances of bulk heterojunction solar cells. Materials Chemistry Frontiers, 2019, 3 (8), pp.1632-1641. 10.1039/C9QM00191C . hal-03085960

\section{HAL Id: hal-03085960 https://hal.science/hal-03085960}

Submitted on 22 Dec 2020

HAL is a multi-disciplinary open access archive for the deposit and dissemination of scientific research documents, whether they are published or not. The documents may come from teaching and research institutions in France or abroad, or from public or private research centers.
L'archive ouverte pluridisciplinaire HAL, est destinée au dépôt et à la diffusion de documents scientifiques de niveau recherche, publiés ou non, émanant des établissements d'enseignement et de recherche français ou étrangers, des laboratoires publics ou privés. 


\section{Materials Chemistry Frontiers}

\section{ARTICLE}

\section{Influence of traces of oxidized polymer on the performances of bulk heterojunction solar cells}

Received 00th January 20xx, Accepted 00th January 20xx

DOI: $10.1039 / x 0 x \times 00000 x$

\author{
Anthony Perthué ${ }^{a}$, Thérèse Gorisse ${ }^{b}$, Hugo Santos Silva ${ }^{c}$, Didier Béguéc, Agnès Rivaton ${ }^{\dagger a}$, Guillaume \\ Wantz $^{\text {tb }}$
}

\begin{abstract}
Organic Photovoltaic (OPV) is facing with the key challenge of making efficient and stable devices with organic materials, which are susceptible to undergo photodegradation in the presence of atmospheric oxygen. It is therefore essential to determine to which extent a minimal oxidation for the donor material used in the active layer results in solar cell's performance loss. Here we mainly focused on thieno[3,4-b]thiophene-alt-benzodithiophene polymer (PTB7) to be compared to well known poly(3-hexylthiophene) (P3HT). The complexity of the PTB7 chemical structure, based on benzodithiophene (BDT) and thienothiophene (TT) alternation and flanked with alkoxy and alkyl side-chains, necessitates the re-investigation of the first step of the photooxidative process. It is shown that neither intrinsic photochemical process nor the presence of an alkoxy side-chain are critical for the photostability. The high initial sensibility of PTB7 in photooxidative conditions is related to singlet oxygen attack on the conjugated backbone giving rise to the formation of carbonylated species. In a second part, it is shown that traces of PTB7 oxidation, resulting from processing or very short irradiation under ambient air, results in a significant drop in solar cells performance. We also show that the easiness of PTB7 photooxidation is higher than the one of P3HT in line with the higher instability of PTB7-based solar cells. The novel bottom-up approach implemented in this work reveals the importance of traces of polymer oxidation products in altering the solar cells efficiency. The use of unstable materials is susceptible to play a key role in the poor initial performances and/or reduced lifetimes of organic solar cells.
\end{abstract}

\section{Introduction}

Organic solar cells (OSC) technology enables the development of flexible, lightweight and transparent modules. ${ }^{1-4}$ There have been intense research efforts devoted to increase the ability of OSC to convert sunlight with high power conversion efficiency (PCE). ${ }^{5,6}$ In recent years, research work was mainly focused on the improvement of the absorbing material used in the active layer with the development of the so-called low band-gap copolymers based on the alternation of donor-acceptor moieties. ${ }^{7}$ PTB7 a thieno[3,4b]thiophene-alt-benzodithiophene polymer is one of the most famous low band-gap copolymers with achieved efficiencies of up to $9 \%{ }^{8-9}$ The backbone structure of PTB7 is complex, based on the

a. Université Clermont Auvergne, CNRS, SIGMA Clermont, Institut de Chimie de Clermont-Ferrand, UMR 6296, F-63000 Clermont-Ferrand, France.

b. Univ. Bordeaux, IMS, CNRS, UMR 5218, Bordeaux INP, ENSCBP, F-33405 Talence, France

c. CNRS/ Univ Pau \& Pays Adour/E2S UPPA, Institut des Sciences Analytiques et de Physico-Chimie pour l'Environnement et les Matériaux, UMR 5254, 64000, Pau, France

† E-mail : agnes.rivaton@uca.fr \& guillaume.wantz@enscpb.fr

Electronic Supplementary Information (ESI) available: UV-Vis spectra of PTB7 films; infrared spectra of PTB7; HS-SPME-GC-MS analysis; Normalized photovoltaic characteristics of solar cells; Bond dissociation energies; Electrophilic character See DOI: $10.1039 / x 0 \times x 00000 x$ combination of two units: thienothiophene (TT) and benzodithiophene (BDT). The BDT unit is flanked by two alkoxy sidechains whereas the side-chain of the TT unit is linked to the backbone by an ester group (Figure 1). Breakthroughs in OSCs stability remain necessary before large scale production of this promising cost-effective renewable electricity generation technology. Beyond successful attempts to address the stability issues such as using inverted architectures, stable electrode materials or ultra-barrier encapsulation, the ultimate OSCs lifetime is limited by the stability of their organic active components. Some studies have revealed a relatively low stability of devices based on PTB7 and of PTB7 deposits under illumination. ${ }^{10-11}$ Recent results evidenced the role played by the polymer chemical structure in the UV-degradation resistance under inert atmosphere of bulk heterojunction solar cells. ${ }^{12}$ Environmental stress like air exposure combined with illumination drastically increases the instability of organic materials and related devices. It should be noted that a wide variety of parameters, including the molecular weight and the dispersity of the polymer ${ }^{13,14}$, the nature of solvent used for film deposition or the use of high boiling point solvent additives ${ }^{15}$, were shown to dramatically impact the photochemical stability of active layers. Therefore, with the aim of making efficient and stable devices with readily photooxidable polymers, a key issue is the 
understanding of the effects of a small amount of oxidized polymer incorporated in the active layer of solar cells. On top of that, little is known on the photodegradation mechanisms responsible for the polymer early step degradation. In what operating conditions is the polymer unstable? What is the vulnerability point of the chemical sructure? Which transient species are involved in the photodegradation process? Here are some of the questions that we try to answer in this study.

Photodegradation is in essence the effect of light on the material (intrinsic photochemistry), the combination of oxygen and/or water with light exposure (photo-oxidation) being susceptible to drastically impact the intrinsic photochemical processes (also called photolytical processes). ${ }^{16}$ In the recent years, several research groups have investigated the PTB7 underlying degradation mechanisms by experimental or modelling approaches, without reaching a consensus. Indeed, due to the complexity of the chemical structure of PTB7 (and the same is true for most of the recent push-pull low band-gap copolymers) numerous and sometimes conflicting mechanisms were suggested to account for the PTB7 photochemical reactivity. Darlatt et al. ${ }^{17}$ and Shah et al. ${ }^{18}$ have focused on the intrinsic light induced degradation of PTB7 and suggested different processes based on experimental study and Density Functional Theory (DFT) modelling respectively. In the same way, different mechanisms were proposed by Kettle et al. ${ }^{19}$ Son et al. ${ }^{11}$, Alem et $a .^{20}$ and Razell-Hollis et al. ${ }^{21}$ to explain the photodegradation of PTB7 when light exposure is performed at ambient air (photo-oxidation).

Answering the crucial issue, dealing with the effect of donor material degradation on OSCs performances, is quite challenging: all the components of the multilayer architecture of OSCs are prone to degrade. Studies focused on the stability of devices based on PCDTBT (poly[N-9'"-hepta-decanyl-2,7-carbazole-alt-5,5-(4',7'-di-2thienyl-2', 1', $3^{\prime}$-benzothiadiazole)], another well-known conjugated polymer, suggested that PCDTBT degradation within the active layer of devices occurs under operating conditions, and that higher polymer molecular weights and inverted architectures enhance the stability of devices. ${ }^{22}$ But it is crucial to investigate further, and it is what we propose in this work using PTB7 as prototypical low bandgap polymer.

In the first part of this paper, we reconsider the mechanisms proposed for PTB7 degradation ${ }^{11,17-21}$ based on new experimental results obtained by combining IR analysis of thin films with DFT modelling and with the effect of chemically generated singlet oxygen. We also compared PTB7 to another polymer with a slight different chemical structure: PTB7-Th (also known as PBDTTT-EFT or PTB7-Th in various reports, see Figure S1). On PTB7-Th, the BDT side chain is linked with a thiophene instead of an ether to the backbone. The effect of PCBM (phenyl- $\mathrm{C}_{61}$-butyric acid methyl ester) fullerene derivative on PTB7 photodegradation is also reconsidered. In a second part, we implement a new bottom-up approach $^{23}$ to directly evaluate the impact of PTB7 deposit and minutes photo-oxidation on the efficiency of devices. The same experiment was also performed and compared with poly(3hexylthiophene) $\mathrm{P} 3 \mathrm{HT}$, the work-horse of polymer photovoltaic research. Finally, we show that the oxidation products, even in very low concentration, significantly impact the performances of solar cells.

\section{Results and discussion}

Photochemical instability of PTB7. The irradiation of conjugated polymer thin films and tracking the photobleaching over time, i.e. the rate of absorption loss, allows to quickly screen their photostability. ${ }^{24-25}$ The loss of absorption is related to a loss of conjugation resulting from photochemical reactions. Whether irradiation is performed in absence of oxygen (hereafter called photolysis) or under ambient air (hereafter called photooxidation), the photobleaching rate allows to quickly evaluate the intensity of different degradation mechanisms: intrinsic light degradation resulting from the light exposure alone or the so-called photooxidative degradation in the presence of oxygen.

Absorption spectra of PTB7 deposits, irradiated either under ambient conditions in air or encapsulated in a glass tube sealed under secondary vacuum were periodically measured to track the decrease of the visible absorption with time (see ESI, Figure S2). Irradiation in vacuum-sealed glass tubes was performed in order to simulate the conditions of ultra-barrier encapsulated solar cells and to address the issue of intrinsic photo-degradation.

In order to compare the photobleaching rates between the two different environments, the normalized absorbance versus time is plotted in Figure 1. As currently observed for other conjugated polymers $^{26-28}$ PTB7 essentially undergoes a very slow decrease of its visible absorption in deoxygenated environment while fast absorption loss, within hours, occurs in the presence of oxygen. The first crucial issue is to determine the underlying degradation mechanisms and the corresponding Achilles' heel of the PTB7 chemical structure.

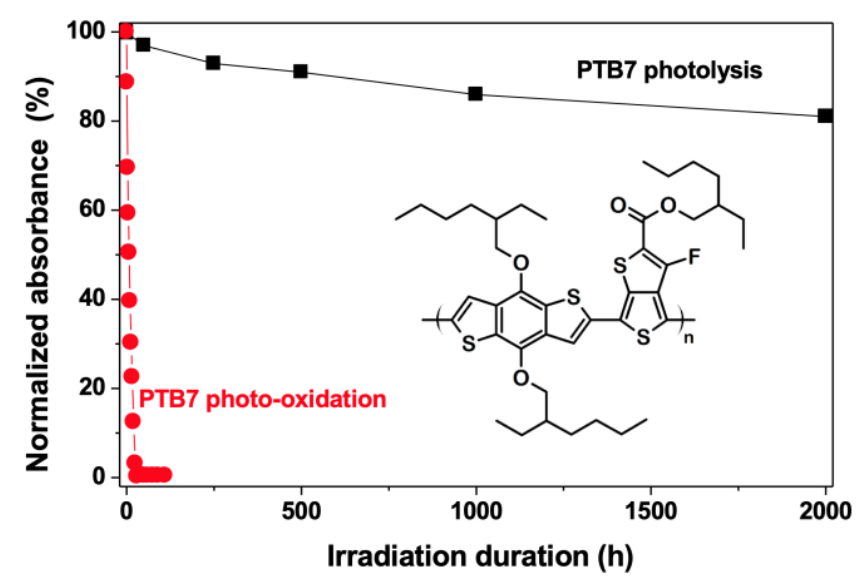

Figure 1. Normalized absorbance loss (maximum absorbance) of PTB7 films submitted to irradiation in ambient air (photooxidation, red symbol) and in deoxygenated atmosphere (photolysis, black symbol). Inset shows the chemical structure of PTB7. 
Darlatt et al. studied by ultraviolet photoelectron spectroscopy (UPS) and S 2p X-ray photoelectron spectroscopy (S 2p XPS) the effect of the irradiation wavelength on the PTB7 stability, in conditions where oxygen and moisture are absent. ${ }^{17}$ They concluded that photons of wavelengths $>320 \mathrm{~nm}$ provoke no significant degradation (at shorter irradiation wavelength, PTB7 degradation would only concern the $S$ atom of the structure). UPS and XPS are very sensitive methods but, as surface analysis techniques, they probe only the first few nanometres of exposed deposits. In our experiment the encapsulating glass filters the radiations below $320 \mathrm{~nm}$. Nevertheless, Figure 1 clearly shows that prolonged exposure in deoxygenated atmosphere provoked a decrease of the UV-visible absorbance of the PTB7 deposits revealing a reduction of the conjugation length. IR spectra reported hereafter (Figure 2) confirm that prolonged exposure in deoxygenated atmosphere induces a decrease of the band at 1568 $\mathrm{cm}^{-1}$ ( $\mathrm{C}=\mathrm{C}$ stretching vibration of the polymer backbone) related to the conjugated skeleton. UV-Vis and IR (Infrared) spectroscopy probes the whole thickness of irradiated films ( $100 \mathrm{~nm})$. The remaining question is which part of the polymer, if there is one, could be specifically responsible for this evolution?

Shah et $a l$. used $a b$ initio simulations to investigate the intrinsic light induced degradation of PTB7 at the atomistic level. ${ }^{18}$ They have modelled some reversible and irreversible degradation pathways, all of them being linked to the alkoxy side-chain on the BDT unit. Irreversible processes would lead to the formation of defects such as changes in the alkyl side-chain structure, formation of $-\mathrm{OH}$ and $\mathrm{C}=\mathrm{O}$ groups. The involvement of the two first is not observed in the IR spectra reported in Figure 2. As we clearly observe no modification in the alkyl stretching vibration domain (3000-2700 $\mathrm{cm}^{-1}$ ) and no increase of absorbance in the hydroxyl domain (3700$3200 \mathrm{~cm}^{-1}$ ), the occurrence of these theoretical rearrangements (if they exist) is fairly low. Concerning the formation of new $\mathrm{C}=\mathrm{O}$ groups, the benzoquinone species suggested by Shah et al. ${ }^{18}$ are usually observed at $\sim 1660 \mathrm{~cm}^{-1}$. ${ }^{29}$ No clear evolution is observed on the IR spectra. The formation of these benzoquinone species is either not significant or eventually overlapped by the pristine ester band.

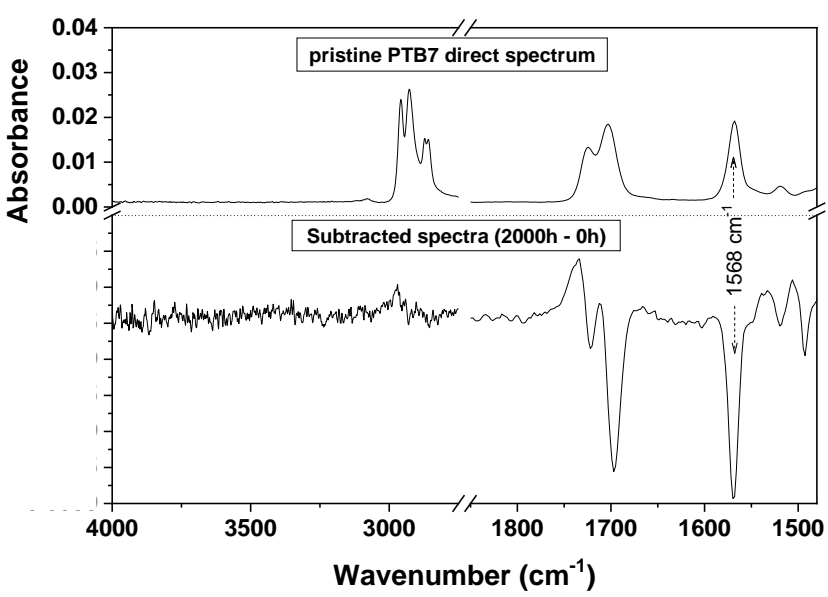

Figure 2. Infrared spectra of PTB7 submitted to photolysis; direct spectrum of pristine PTB7 (top); subtracted spectra: spectrum of PTB7 photolyzed $2000 \mathrm{~h}$ - pristine PTB7 spectrum ( $0 \mathrm{~h})$ (bottom).

The carbonyl region shows the ester vibration on the TT unit of the pristine structure $\left(1680-1750 \mathrm{~cm}^{-1}\right)$. To get more insight in the evolutions provoked by exposure in this domain, we subtracted spectra (irradiated - pristine). The modifications observed are characteristic of a shift of the ester vibration bands to higher wavenumbers. It is worth noting that the same evolution was observed with PTB7-Th submitted to irradiation in deoxygenated atmosphere and therefore cannot be related to a hypothetical modification of the alkoxy group which is only present in the PTB7 structure. The shift of the ester band to higher wavenumbers was also observed under every stress conditions (temperature and light w/ or w/o oxygen) for both PTB7 and PTB7-Th (see Figure S3 in ESI and Figure 4a presented later), and the spectroscopic modifications observed during photo-oxidation under ${ }^{18} \mathrm{O}_{2}$ presented thereafter (Figure 4b) allow us to assign the ester band modification to an intrinsic re-organization. The shift of the ester band to higher wavenumbers could suggest that its chemical environment is modified: possible interaction with the $\mathrm{F}$ atom could come into play. $^{29}$

Coming back to the alkoxy group (-OR) of PTB7, Kettle et al. suggested that light exposure provoked the homolytical scission of the BDT-OR bond, even in the absence of $\mathrm{O}_{2} .{ }^{19}$ We were able to calculate at the DFT level of theory the energy of the BDT-OR bond which is only of $55 \mathrm{kcal}^{\mathrm{mol}}{ }^{-1}$ thus suggesting that all the photons of $\lambda<520 \mathrm{~nm}$ are able to provoke the homolytic scission of the BDTOR bond (see also Table S2 in supporting information). It is usually observed that when pendant groups are cleaved from the main chain, part of them is susceptible to migrate out of the film in the gas phase. ${ }^{30}$ But this process is not significantly occurring in our irradiation conditions, as no modifications in the alkyl side chain stretching vibration domain $\left(2950-2850 \mathrm{~cm}^{-1}\right)$ can be observed even after prolonged exposure $(2000 \mathrm{~h})$ as shown in Figure 2. To explore this issue, we have submitted PTB7-Th films to irradiation in the same conditions. Data reported in Table S2 clearly show that the scission of the alkyl side chain requires more energy in the case of PTB7-Th (109 $\mathrm{kcal} \mathrm{mol}^{-1}$ ) compared to PTB7, but still may be cleaved by UV photons $(<330 \mathrm{~nm}$ ). Curves reported in Figure $\mathbf{3}$ show that the decrease of the visible absorbance occurs at the same rate in PTB7 and PTB7-Th deposits. Interestingly the presence of PCBM slows down the PTB7 and PTB7-Th absorbance loss, and the same effect was previously monitored when $\mathrm{P} 3 \mathrm{HT}$ and P3HT:PCBM films were submitted to prolonged exposure in the absence of oxygen. ${ }^{31}$

One could hypothesize that PTB7 and PTB7-Th have the same evolution as the one postulated for $\mathrm{P} 3 \mathrm{HT}$ irradiated in deoxygenated atmosphere ${ }^{32}$ : the homolytical scission of the sidechain could be followed by addition on the conjugated backbone. Such saturation reaction which induces a reduction of the conjugation length of the pi-conjugated system could account for 
the decrease in the visible absorbance observed in the UV-visible spectra. The stabilising effect provided by the fullerene derivative in polymer:blend active layer was then ascribed to its ability to scavenge free radicals, hindering thus the radical-based degradation mechanism of polymers.

Should we conclude that the degradation observed in deoxygenated conditions is only related to these supposed intrinsic photo-degradation processes? It cannot be ruled out that oxygen traces are still remaining in the polymer films especially in our conditions of encapsulation and analysis which inevitably involve the contact with atmospheric oxygen. To infirm or confirm this hypothesis, the influence that the (re)encapsulation process may have on the introduction of oxygen was assessed. To do this, polymer films were encapsulated in glass tube under secondary vacuum and analyzed after $2000 \mathrm{~h}$ of exposure, with no intermediate steps. Interestingly, an Absorbance loss of only $6.5 \%$ was observed after completion of $2000 \mathrm{~h}$ of photolysis to be compared with the $12 \%$ obtained for the same batch of sample sealed in the exact same conditions but opened and re-sealed multiple times during the $2000 \mathrm{~h}$ of irradiation (see Figure 3 bottom). The different extents of degradation in the two cases indicate that each time the tube is opened to analyse the sample, a certain amount of oxygen is introduced and trapped in the polymer film. Samples analysed at several irradiation steps have been in contact with higher amounts of oxygen, thus explaining the higher absorption loss.

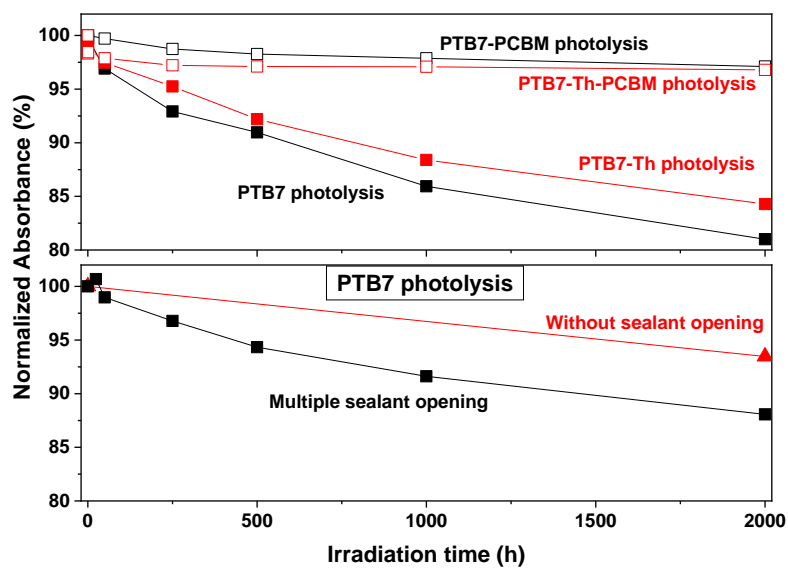

Figure 3. Normalized Absorbance loss (maximum absorbance) of PTB7, PTB7-Th PTB7:PCBM and PTB7-Th:PCBM deposits submitted to irradiation in deoxygenated atmosphere (top). Normalized absorbance loss for PTB7 films in photolysis experiment with or without multiple sealant apertures (bottom)

It is therefore possible to conclude that contrary to what might have been feared on the basis of theoretical calculations, the presence of $\mathrm{O}$ atom between the side chain and the BDT units is not the crucial point that renders PTB7 vulnerable under light exposure in deoxygenated atmosphere. Our main conclusion is that the chemical structure of PTB7 is intrinsically resistant to light exposure in optimal encapsulation conditions. However, oxygen traces in combination with light probably provoke the tiny chemical structure evolutions observed upon photolysis experiments. Therefore, if atmospheric oxygen has such a huge effect on PTB7, it seems appropriate to elucidate the reason why. This is the subject of the following section.

Previous studies devoted to the photooxidation of PTB7 suggested an attack by singlet oxygen, but the postulated oxidation site and resulting products were different. Thanks to sensitization techniques performed in solution combined with molecular orbital calculations, Son et al. suggested that singlet oxygen attacks the TT moieties of the polymer, and proposed that the thienyl ring directly linked to the polymer main chain is most likely the site of a [2+4] cycloaddition. ${ }^{11}$. Alem et al. proposed on their side that singlet oxygen can react with the BDT unit of PTB7 according with the wellknown behaviour of anthracene with ${ }^{1} \mathrm{O}_{2}{ }^{20}$ Razzell-Hollis et al. studied the photooxidative degradation of PTB7 using Raman spectroscopy combined with DFT modelling. ${ }^{21}$ Short exposure in the laser beam of the Raman apparatus provoked a shift of a band attributed to BDT unit without intensity decrease. This observation has led the authors to suggest that the initial oxidation of PTB7 involves the hydroxylation of the BDT unit of PTB7 without absorbance decrease as a result of singlet oxygen attack. It is worth recalling that hydroxyl groups formation was not directly observed and that the UV-Vis spectra were not recorded in parallel to the Raman spectra. Additionally, no detailed mechanism was proposed to explain how singlet oxygen attack provokes PTB7 hydroxylation.

To get deeper information in the photooxidative mechanism, we tackled the problem from the direct observation of the effect of short time exposures using both UV-vis monitoring and IR spectroscopy which is a very efficient method to track the formation and identification of oxidation products of polymers. We also performed thermooxidation experiments as well as exposure in ${ }^{18} \mathrm{O}_{2}$ atmosphere, and used a new method allowing to assess singlet oxygen involvement in the photo-oxidation of conjugated materials. ${ }^{33}$

Photo-oxidation (Suntest device, samples temperature $\sim 37^{\circ} \mathrm{C}$ ) and thermo-oxidation (ventilated oven at $100^{\circ} \mathrm{C}$ ) of PTB7 deposits induce a progressive loss of the UV-visible absorbance, indicating that the pi-conjugated backbone is broken during ageing (see ESI, Figures S2 and S4). Photo-oxidation and thermo-oxidation also result in rapid and noticeable modifications in the IR spectrum of PTB7. Upon ageing, a rapid disappearance of the various functional groups of PTB7 is observed. At the same time, new absorption bands in the carbonyl, hydroxyl and fingerprint regions develop. Figure 4a (subtracted spectra, direct spectra are reported in ESI, Figure S5) compares the IR modifications for PTB7 samples thermooxidized in air at $100{ }^{\circ} \mathrm{C}$ or photooxidized in Suntest device in air. As observed previously upon irradiation in deoxygenated atmosphere, photo- and thermo-oxidation induce the rearrangement of the ester group. The increase of absorbance observed after long duration exposure $(>3 \mathrm{~h})$ in the hydroxyl region $\left(3200 \mathrm{~cm}^{-1}\right)$ could be attributed to the $\mathrm{OH}$ vibration of carboxylic acids. Their $\mathrm{C}=\mathrm{O}$ vibration is most likely overlapped by the initial ester band of the TT moiety as confirmed below with ${ }^{18} \mathrm{O}_{2}$ photo-oxidation experiments (Figure 4b). Photo- and thermo-oxidation also lead to the formation 
of numerous bands in the fingerprint region, as well as the decrease of the intensity of all the PTB7 bands (conjugated skeleton and sidechains). But the most noteworthy aspect of very short duration photooxidation ( $1 \mathrm{~h}-3 \mathrm{~h}$ ) is the formation of two bands at 1630 and $1660 \mathrm{~cm}^{-1}$, whereas no increase of absorbance in the hydroxyl domain is observed. The band at $1630 \mathrm{~cm}^{-1}$ is not observed upon thermo-oxidative degradation. We have checked that post-thermal treatment at $100^{\circ} \mathrm{C}$ does not decrease the intensity of this band. It is then possible to conclude that its formation involves pure photochemical processes or photochemically produced transient species. The $1630 \mathrm{~cm}^{-1}$ band appears in the domain of carbonyl products and/or double bonds. To determine which explanation is the most likely, we performed the same photo-oxidation experiment but under ${ }^{18} \mathrm{O}_{2}$ atmosphere. As observed in Figure $\mathbf{4 b}$, the shift of the band from $1630 \mathrm{~cm}^{-1}$ in atmospheric conditions $\left({ }^{16} \mathrm{O}_{2}\right)$ to $1604 \mathrm{~cm}^{-1}$ in ${ }^{18} \mathrm{O}_{2}$ atmosphere allows one to claim that this band is related to carbonyl species created after incorporation of atmospheric oxygen in the chemical structure of PTB7. Furthermore, under ${ }^{18} \mathrm{O}_{2}$ irradiation we also observed the formation of a band centred at $1664 \mathrm{~cm}^{-1}$. Assuming that the fixation of ${ }^{18} \mathrm{O}_{2}$ produced a $40 \mathrm{~cm}^{-1}$ shift, as theoretically estimated by the use of the classical equation between the frequency and the reduced mass ${ }^{34}$, the corresponding carbonyl vibration should be found at $1704 \mathrm{~cm}^{-1}$ under ${ }^{16} \mathrm{O}_{2}$ irradiation (vibration range of CO group of carboxylic acids ${ }^{29}$ ). This band is overlapped by the ester vibration and thus it is not observed in ambient air $\left({ }^{16} \mathrm{O}_{2}\right)$ irradiation conditions. This information confirms our previous attribution of an $\mathrm{OH}$ vibration $\left(3200 \mathrm{~cm}^{-1}\right)$ to carboxylic acids. The ester vibration bands modification on its side is clearly not modified by the irradiation under ${ }^{18} \mathrm{O}_{2}$, thus confirming that this evolution results from an intrinsic structural modification of the ester moieties. To complete the analysis of the IR spectra evolution, the decrease of the alkyl bands intensity $\left(2850-2950 \mathrm{~cm}^{-1}\right)$ is correlated with the detection of low molecular weight oxidation products in the gas phase (see ESI, Figure $\mathbf{S 6}$ and Table S1). Moreover, the oxidation of the sulfur atom of the thiophene moieties leads to the formation of sulfinic ester as shown by the formation of a band at $620 \mathrm{~cm}^{-1}$ after long photooxidation duration (> $30 \mathrm{~h}$ ) (see Figure S7 in ESI).

Finally, it was necessary to evaluate if the carbonyl products created at $1630 \mathrm{~cm}^{-1}$ are assigned (or not) to singlet oxygen attack on PTB7 structure. Figure 4c shows the IR spectra of PTB7 chemically treated with singlet oxygen according to a new protocol that has been recently developed. ${ }^{33}$ Clearly, singlet oxygen attack result in the development of the band at $1630 \mathrm{~cm}^{-1}$ thus allowing to conclude that i) singlet oxygen attack leads to the formation of carbonyl products and not hydroxyl adducts, ii) the very first step of PTB7 photooxidation involves singlet oxygen attack.
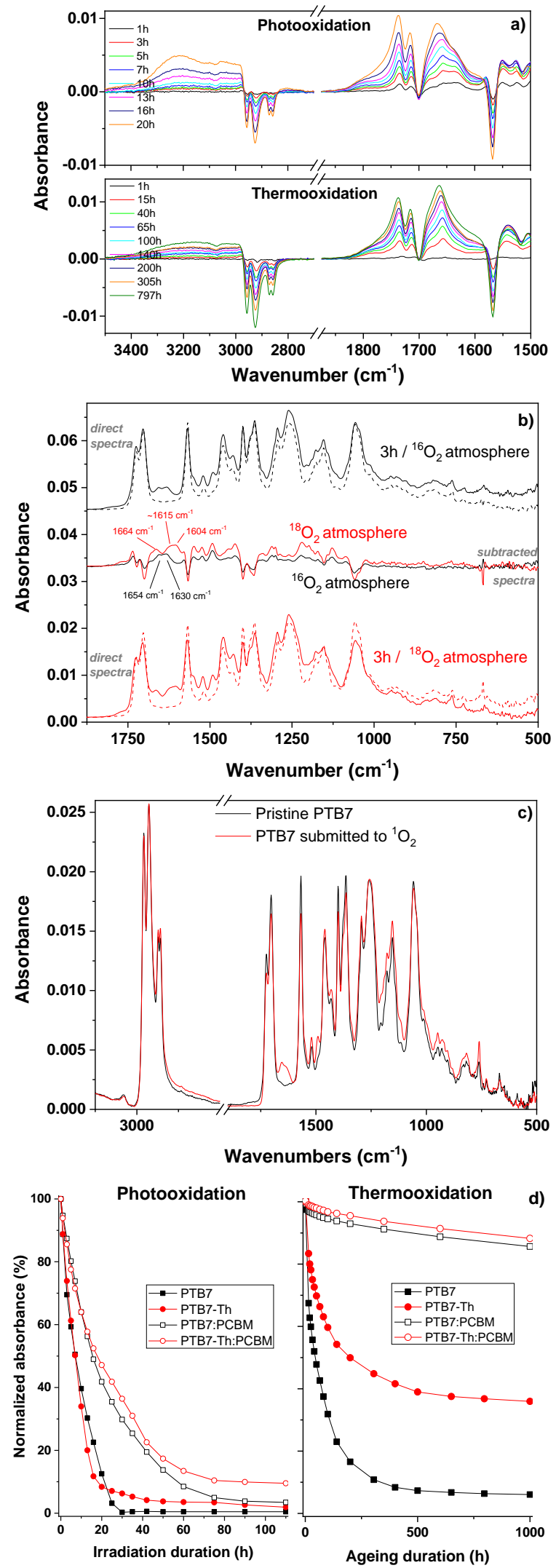

Figure 4. (a) Evolution of the subtracted IR spectra of PTB7 during photo-oxidation and thermo-oxidation; (b) Comparison between $3 \mathrm{~h}$ irradiation under ${ }^{16} \mathrm{O}_{2}$ atmosphere (black) and ${ }^{18} \mathrm{O}_{2}$ atmosphere (red) respectively; Direct spectra (full line: before exposure; dash line: after $3 \mathrm{~h}$ exposure) (top and bottom); Subtracted spectra ( $3 \mathrm{~h}-\mathrm{Oh}$ ) (middle). (c) Singlet oxygen reactivity on PTB7. (d) Normalized Absorbance loss (maximum absorbance) of PTB7, PTB7-Th, PTB7:PCBM and PTB7-Th:PCBM deposits submitted to photooxidation (left) and thermooxidation (right). 
Singlet oxygen is a dienophile and an electrophile which is going to attack the electron-rich regions of PTB7. In order to probe the most probable regions of the molecule susceptible to undergo an oxygen attack, we have calculated and plotted the Condensed Fukui Functions (CFF) for both molecules (PTB7 and PTB7-Th structures). In zeroth order, it would be enough to calculate the electronic density of the HOMO orbital but this approach does not take into account any orbital relaxation. The CFF are able to describe how the attack probability upon a definite reaction is distributed on the molecular coordinates. Three CFF exist, $f^{+}, f$ and $f^{0}$, describing, respectively, the easiness of the molecule to undergo an electrophilic, nucleophilic or a radial attack. Generally speaking, for a molecule having $\mathrm{N}$ electrons in its ground state, these functions are calculated as follows:

$$
\begin{gathered}
f_{k}^{+}=q_{k}(N+1)-q_{k} \\
f_{k}^{-}=q_{k}-q_{k}(N-1) \\
f_{k}^{0}=\frac{1}{2}\left(f_{k}^{+}+f_{k}^{-}\right)
\end{gathered}
$$

where $q_{k}$ is the charge of the $k$-th atom of the molecule for a cationic $(\mathrm{N}-1)$ or anionic $(\mathrm{N}+1)$ electron states. Oxygen being an electrophile, we need to estimate the propensity of the molecule to suffer such electrophilic attack. In this way, plotting $f$ can indicate the most probable regions of the molecule to do so. Thus, one can note from Figure 5 that the BDT donor group is the one that is most probable to be attacked by singlet oxygen in PTB7 and in PTB7-Th structure. Our conclusion obtained by modelling is in line with the one of Razell-Hollis et al.. ${ }^{21}$ We have also calculated the electrophilicity of each one of PTB7 and PTB7-Th structures in an attempt to quantify their photo-oxidation easiness. The full details can be found in the ESI, but briefly: the electrophilicity can be understood as the ratio between the eagerness of a molecule to capture an additional electron from its environment (chemical potential) and its resistance to back-transfer it. In this way, the higher the electrophilicity of a compound is, the higher also is its resistance to an electrophile attack. Our calculations show that PTB7-Th and PTB7 have very similar electrophilicities which very little differences do not allow us to conclude about which molecule is the least probable to undergo an electrophile attack.

The identification of by-products is essential to validate a proposal of reaction mechanism. Based on modelling of the Raman spectra of PTB7 deposits irradiated in pure oxygen or in situ in the Raman apparatus, Razell-Hollis et al. suggested that oxygen attack on the BDT unit of PTB7 results in the mono-and di-hydroxylation of the thiophene rings of the BDT unit. ${ }^{21}$ In our conditions representative of outdoor exposure we observe the formation of carbonyl products, not hydroxyl groups. Carbonylated species identified on the IR spectra at $1630 \mathrm{~cm}^{-1}$ in Figure 4 probably result of the decomposition of highly unstable primary products issue from singlet oxygen attack (typically endoperoxide (R-O-O- $R^{\prime}$ ), hydroperoxyde (R-O-O-H...). ${ }^{35-36}$ What is certain, however, is that carbonylated species identified on the IR spectra at $1630 \mathrm{~cm}^{-1}$ are not issue from mono- or dihydroxylated structures modelled by Razell-Rollis et al. $^{21}$ as these structures can be considered as rather stable in our mild irradiation conditions.

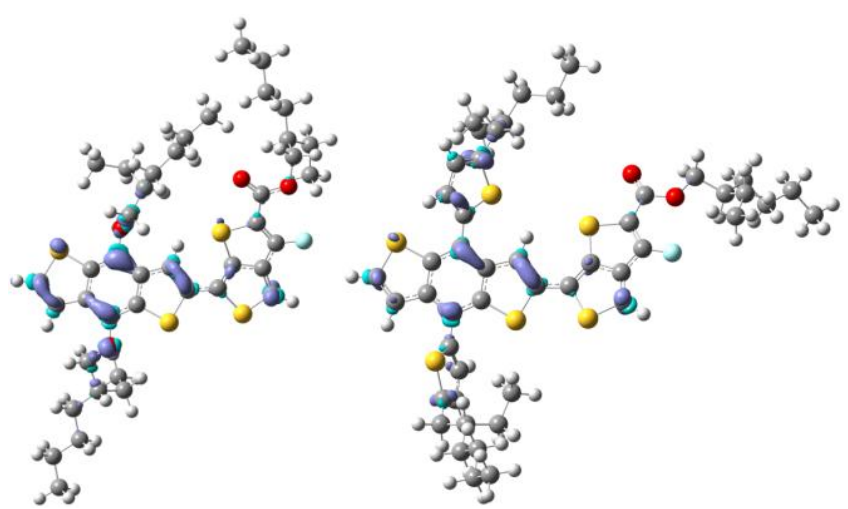

Figure 5. PTB7 (left) and PTB7-Th (right) plotting of $f$ Condensed Fukui Function indicating the most probable regions of the molecule to undergo an electrophilic attack by singlet oxygen

While it has now been proven that PTB7 degradation is initiated by singlet oxygen attack one can ask about the role of the free-radical chain oxidation route which is generally thought to lead the polymer photo-oxidation and starting with a hydrogen abstraction. It appears that the carbonyl products observed at $1630 \mathrm{~cm}^{-1}$ does not accumulate much in the film but other degradation products observed at 1660 and $1790 \mathrm{~cm}^{-1}$ continue to be formed. Those products are willingly attributed to find their origin either from the free-radical chain oxidation mechanism, which can take place in parallel to the singlet oxygen reactivity, or from the next steps occurring after singlet oxygen reactivity on PTB7. Two action modes are known concerning singlet oxygen reactivity: the first one being the formation of endoperoxide species and the second one being the formation of a hydroperoxide. Both mechanisms can lead to the formation of radicals which will in turn start a free-radical oxidation route by hydrogen abstraction on the side chain of the polymer, finally conducting to the oxidation of the sulphur atoms of the thiophenic moieties (see Figure S7) as reported for many conjugated polymers. ${ }^{25,30,37}$. Our results differ from the literature on one point though: the PCBM effect. It appears that, in our irradiation conditions, PCBM increases the PTB7 and PTB7-Th photostability which could validate the involvement of radical process inhibited by the radical scavenging properties of the fullerene cage (see Figure 4d). Interestingly Razzell-Hollis et al. ${ }^{21}$ and Tremolet de Villers et $a l^{38}$ observed no photo-stabilizing effect of $\mathrm{PC}_{71} \mathrm{BM}$ on respectively PTB7 and PTB7-Th photo-oxidation. The degradation conditions were different in both cases: for the former, pure oxygen and the laser beam of the Raman apparatus were used and remaining di-iodooctane (DIO) as processing co-solvent might have drastically impacted PTB7 stability. ${ }^{15,39,40}$ For the latter, the thickness of the polymer deposits compared to the one of the blend (twice the thickness) may have played a significant role in the photo-oxidation rate as previously reported. Another possibility is that $\mathrm{PC}_{61} \mathrm{BM}$ used in the present study has a much better stabilizing 
effect due to a higher electron affinity as this goes hand-in-hand with a lower rate of blend photobleaching according to Hoke et al.. $^{41}$

Importantly, the data reported in Figure 4 d shows that the photooxidation rate of PTB7 and PTB7-Th are roughly the same, thus indicating that the presence of a thiophenyl group or $\mathrm{O}$ atom linking the side chain to the BDT unit does not play a crucial role. However, DFT modelling reported in ESI show that the link between the BDT unit and the alkyl chain plays a key role in the oxidability of the side-chain versus a chain radical oxidation. Clearly the presence of the thiophenyl group in PTB7-Th renders the $\mathrm{H}$ atom on the $\mathrm{CH}_{2}$ in alpha position quite labile. Therefore, all these results suggest that the key point in low band-gap polymers based on the BDT-TT alternation is their easiness to be attacked by singlet oxygen, and that the nature of the side chain plays a minor role.

Effect of PTB7 oxidation traces on OSC efficiency. Finally, the important question to be addressed is to determine if small amounts of oxidation products, unavoidable because of the easiness of PTB7 photooxidation, could alter the electronic properties of the devices. The additional issue here is to determine if it is the amount of oxidation products or their chemical structure that plays the most important role. It was therefore decided to compare the effect of very short photooxidation duration of PTB7 to the one of $\mathrm{P} 3 \mathrm{HT}$ as the photooxidative degradation of this latter does not involves singlet oxygen. ${ }^{33,42-43}$ To determine the impact of PTB7 and P3HT oxidation traces on OSC performances, we have implemented a bottom-up approach depicted in a previous paper. ${ }^{23}$ Thin films of PTB7 and P3HT were first exposed to different photooxidation duration times: from 0 to $20 \mathrm{~min}$ for PTB7, and from 0 to 60 min for $\mathrm{P} 3 \mathrm{HT}$. The duration is longer for $\mathrm{P} 3 \mathrm{HT}$ as this polymer is more resistant to photooxidation compared to PTB7 in terms of photobleaching. This is clearly observed in Figure 6 (left) which shows the decrease of the UV-Vis absorbance of P3HT and PTB7 deposits submitted to short duration photooxidation. The irradiation duration was limited so that the absorbance decrease is minimal. It is noteworthy that after $3 \mathrm{~min} / 20 \mathrm{~min}$ exposure for PTB7 / P3HT respectively the absorbance decrease of the deposit is lower than $2 \%$. In addition, the corresponding level of oxidation is so low that oxidation products were barely observed to be formed for PTB7 by IR spectroscopy (see Figure $\mathbf{S 8}$ in ESI).

After irradiation, polymer thin films were re-dissolved and then blended with $\mathrm{PC}_{61} \mathrm{BM}$ and used to produce inverted bulk heterojunction solar cells. The efficiencies (PCE) of OSCs processed with partially photooxidized P3HT and partially photoxidized PTB7 deposits are presented in Figure 6 (right). Devices with pristine materials are showing PCE of approx. 3.5\% and 6\% with P3HT and PTB7 respectively, values that are very common in the field. Photovoltaic parameters are: short-circuit current (Jsc) of $11.8 \mathrm{~mA}$ $\mathrm{cm}^{-2}$ and $11.6 \mathrm{~mA} \mathrm{~cm}^{-2}$, open-circuit voltage ( $\mathrm{Voc}$ ) of $0.52 \mathrm{~V}$ and 0.72 $\mathrm{V}$, and fill factor (FF) of 0.57 and 0.71 respectively with $\mathrm{P} 3 \mathrm{HT}$ and PTB7. We can observe that quite different photovoltaic performances are obtained when polymers were marginally photooxidized. Indeed, the PCE undergoes a rapid drop: a $20 \%$ decrease of the PCE is observed when solar cells are made with PTB7 and P3HT photooxidized 3 and 20 min respectively; PCE is close to zero after $20 \mathrm{~min}$ of photo-oxidation in the case of PTB7 whereas $60 \mathrm{~min}$ of photooxidation in the case of $\mathrm{P} 3 \mathrm{HT}$ provokes only less than $50 \%$ decrease. Importantly the similarity of the kinetics reported in Figure 6 left (polymer oxidation tracking) and right (devices performances) suggest that the efficiency of OSC performance is clearly related to the level of polymer oxidation.
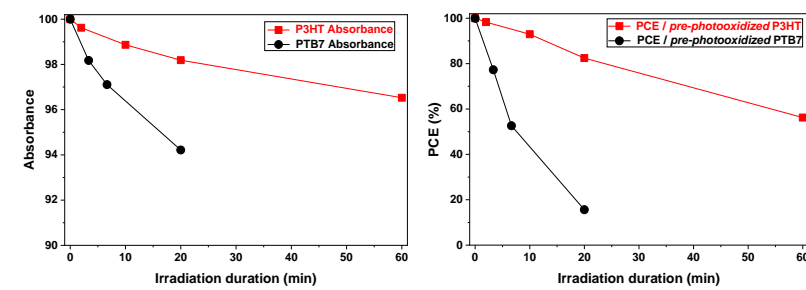

Figure 6. (left) Normalized Absorbance loss (between $100 \%$ and $94 \%$ ) of P3HT and PTB7 deposits submitted to short duration photooxidation. (right) Photovoltaic properties (between $100 \%$ and $0 \%$ ) of solar cells based on partially oxidized PTB7 or partially oxidized P3HT

Note that the scales in Figure 6 (left and right) are very different: between $100 \%$ and $90 \%$ for Absorbance loss (left) and between $100 \%$ and $0 \%$ for Photovoltaic characteristics (right).

To determine whether the chemical structure of oxidation products plays a role in the alteration of the PV properties of the devices, we have reported below the evolution of the main photovoltaic parameters: fill factor (FF), short-circuit current (Jsc) and opencircuit voltage (Voc) of solar cells based on photooxidized PTB7 and photooxidized P3HT (Figure 7). The loss of short circuit current is the most detrimental origin of loss of efficiency. The loss of absorbance is only minimal as can be seen on Figure 6 (e.g. lower than $2 \%$ after $3 \mathrm{~min} / 20 \mathrm{~min}$ exposure for PTB7 / P3HT respectively). It cannot explain on its own the drop of Jsc. As a consequence, the traces of oxidized polymer (P3HT or PTB7) are acting as traps or recombinaison centers. In addition, PTB7 photooxidation involves volatile formation (Figure S6 and Table S1 in ESI) as well as polymer backbone scissions ${ }^{15}$. Such a reduction in molecular weight could also contribute to the decrease of photovoltaic performances, as it has been shown in various studies. $^{13,44,45}$ It is important to notice that here only the polymer was partially oxidized on purpose prior device fabrication, meaning the $\mathrm{PC}_{61} \mathrm{BM}$ was pristine. We also conducted experiments in which the whole $\mathrm{BHJ}$ blend PTB7:PCBM (or P3HT:PCBM) was exposed to gradual photooxidation prior to device fabrication following the same experimental procedure. The results are that the photooxidation of the blend gave the same trend of results (Figure 59) as when the polymer only was oxidized. As said previously blends are also sensitive to oxidation, the presence of fullerene does not completely inhibit the formation of photooxidized products. On top of that, in a previous study, we have shown on a similar protocol that the photooxidized PCBM is also a killer of solar cell performances. ${ }^{23}$ Here, we guess that the blends are containing both: traces of photooxidized polymer and traces of photooxidized 
PCBM. However, it is not stronger with blend. This is the first time it is shown that degradation of performance of polymer solar cells could be related to the polymer oxidation itself as a newly evidence mechanism of degradation in a real operating device.
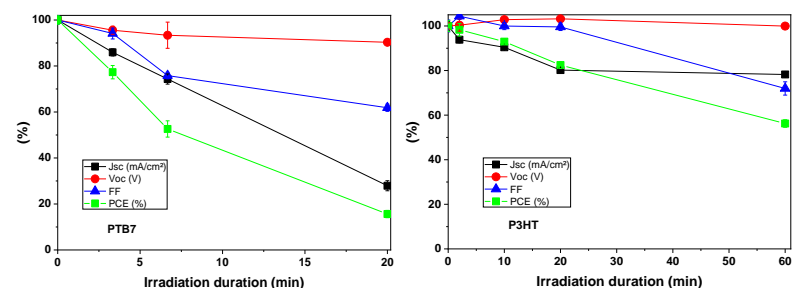

Figure 7. Normalized photovoltaic characteristics (between $100 \%$ and $0 \%$ ) of solar cells based on previously photo-oxidized PTB7 from 0 to $20 \mathrm{~min}$ (left) or P3HT from 0 to 60 $\min$ (right).

\section{Conclusions}

We have shown that PTB7 is steadily oxidized when exposed to the combination of light and oxygen. This vulnerability is coming from the facility of the BDT unit in BDT-TT alternation structures to be attacked by singlet oxygen, thus leading to the formation of carbonylated species. Due to the high "oxidizability" of PTB7, our results suggest that the involvement of intrinsic photochemical processes that can be theoretically modelled should be considered as an epiphenomenon versus the effect of oxidation traces during fabrication or upon operating conditions. A key result highlighted by this study is the demonstration that polymer oxidation traces, resulting from indoor processing or minutes photooxidation, have a dramatic negative impact on the efficiency of PTB7 based solar cells. The bottom-up approach implemented in this work clearly emphases the key role of traces of polymer oxidation product on solar cells efficiency. This degradation mechanism is scarcely ever put forward due to a lack of sensitive methods. Further investigations may be needed to better identify the exact role of polymer oxidation defects in the photovoltaic mechanism. This study should guide the synthesis of novel low band gap polymers that are more resistant to photooxidation, and more particularly not attacked by singlet oxygen, allowing participating in maintaining OSC efficiency over long lifetimes. As we determined that traces of polymer oxidation product act as an important loss mechanism, with the actual materials, ultrabarrier encapsulation is so far mandatory to maximize the actual solar cells durability.

\section{Conflicts of interest}

There are no conflicts to declare.

\section{Acknowledgements}

This work was supported by the Agence Nationale de la Recherche (ANR) through the PROGELEC 2013 program " HELIOS » (ANR-13-PRGE-0006).

\section{Methods}

\section{Materials}

PTB7 and PTB7-Th were purchased from 1-Materials. PCBM was kindly provided by ARMOR collaborators. Chlorobenzene (CB), orthodichlorobenzene (ODCB), chloroform, absolute ethanol, diiodooctane and Zinc di-hydrate acetate were obtained from Sigma Aldrich. $\mathrm{MoO}_{3}$ and $\mathrm{Ag}$ were purchased from Neyco and the ITO-coated glass from Visiontek. ${ }^{18} \mathrm{O}_{2}$ with an isotopic purity of $97 \%$ was obtained from Sigma-Aldrich.

\section{Sample preparation}

Thin film preparation. Deposits on $\mathrm{KBr}$ substrates and solar cells were prepared through spin coating. Large surface area glass plates coated with PTB7, PCBM or PTB7-PCBM blend were prepared by bare-coating according to a method recently described. ${ }^{23}$

Device processing. ITO-coated glass was washed through ultrasonic treatment in soap / de-ionized water solution, in pure de-ionized water and in isopropanol (15 min each) and subjected to UV-ozone for $10 \mathrm{~min}$ to complete the cleaning procedure. The electron transfer layer consists of a 40-nm-thick $\mathrm{ZnO}$ sol-gel layer: zinc acetate dihydrate, dissolved with monoethanolamine (both at $0.15 \mathrm{~mol} \mathrm{I}^{-1}$ ) in absolute ethanol, was spun coat at $2000 \mathrm{rpm}$ for $60 \mathrm{~s}$ on the ITO substrate and annealed at $180^{\circ} \mathrm{C}$ for $1 \mathrm{~h}$. The samples were then transferred into a water- and oxygen-free environment (glove-box). The blends were prepared following the same procedure as described above. After the blend deposition, the substrates were transferred to a thermal evaporator, where the top electrode, $7 \mathrm{~nm}$ of $\mathrm{MoO}_{3}$ and $70 \mathrm{~nm}$ of $\mathrm{Ag}$, was deposited at $3 \times 10$ ${ }^{6}$ mbar. The final device area was $10 \mathrm{~mm}^{2}$, as defined by a shadow mask.

\section{Ageing}

Irradiation. Photodegradation experiments were conducted in a Suntest CPS/XLS Atlas device. A xenon lamp from ATLAS (NXE1700) configured at $750 \mathrm{~W} \mathrm{~m}^{-2}$ in the UV-visible domain $(300-800 \mathrm{~nm}$ ) was provided with it. IR irradiation and UV photons below $300 \mathrm{~nm}$ were cut off thanks to the so-called "daylight filter" from Atlas. A cryostat allows maintaining the Black Standard Temperature (BST) at $60^{\circ} \mathrm{C}$ which corresponds to about $37^{\circ} \mathrm{C}$ in the irradiation chamber. Irradiations in absence of oxygen were conducted by encapsulating the samples in borosilicate tubes sealed under secondary vacuum $\left(10^{-6} \mathrm{~Pa}\right)$ before exposure in the Suntest. Short irradiations were also conducted by enclosing the samples in a borosilicate tube filled with a slight overpressure of synthetic air composed of $20 \%$ of either ${ }^{18} \mathrm{O}_{2}$ or ${ }^{16} \mathrm{O}_{2}$ and $80 \%$ of $\mathrm{N}_{2}$.

Thermal ageing. Thermo-oxidation was conducted in a ventilated oven at a temperature of $100{ }^{\circ} \mathrm{C}$.

${ }^{1} \mathrm{O}_{2}$ treatment. PTB7 and PTB7-Th were submitted to singlet oxygen in chloroform solutions, at ambient temperature and in the dark as already reported for other semi-conducting organic materials. ${ }^{33}$ Singlet oxygen was generated through the cycloreversion reaction 
occurring at ambient temperature of dimethylnaphthalene endoperoxide which was synthesized according to Turro et al. ${ }^{46}$

\section{Characterizations}

Spectroscopy. UV-visible spectra were obtained with a UV2600 spectrophotometer equipped with an integrating sphere from Shimadzu.

Infrared (IR) transmission spectra were obtained using a Thermo Scientific Nicolet 6700 spectrophotometer purged with dry air at a resolution of $4 \mathrm{~cm}^{-1}$ by summing 32 scans.

HS-SPME-GC-MS. HS-SPME-GC-MS (headspace solid-phase microextraction (HS-SPME) coupled with gas chromatography/mass spectrometry (GC-MS)) was employed to collect and analyze the volatile compounds created upon photooxidation of PTB7 films, irradiated in sealed vials. The procedure has been detailed for studies concerning other polymer matrices. ${ }^{47}$

Photovoltaic performances. Current density vs voltage curves were measured for each device using a Keithley 2400 analyser under an AM1.5 solar simulator with a Xenon lamp calibrated with a radiometer (IM1400) at $100 \mathrm{~mW} \mathrm{~cm}^{-2}$. The power conversion efficiency (PCE), fill-factor (FF), short circuit density current (Jsc) and open circuit voltage $(\mathrm{Voc})$ were extracted from these curves. For each condition, 2 substrates, each with four cells with $10 \mathrm{~mm}^{2}$ of surface area, were fabricated. Because a few devices malfunctioned, the average and standard deviations were calculated with between 6 and 8 values.

Modelling. Molecular geometries were optimised within the B3LYP/def2-TZVP Density Functional Theory (DFT) level of theory using the D3BJ dispersive correction to account for long-range corrections in the unrestricted wave-function formalism. The RIJCOSX approximation with the def2-TZVP/C auxiliary basis set was used throughout the calculations. Energy and gradients had their convergence criteria set to very tight. All the calculations were performed using the Orca 3.0.3 software. Whenever needed, molecular orbitals were plotted using a 0.02 isosurface value. The Molecular Electrostatic Potential (MEP) was used to map the Total Electron Density (TED) using a 0.001 isosurface value. Plotting was performed for differences in electrical charge from $-2 \mathrm{E}-2$ to $2 \mathrm{E}-2 \mathrm{e}$. Time-dependent Density Functional Theory (TDDFT) was used in the same level of theory to calculated the UV-VIS electronic transitions as well as to probe the energies of the first excited states. 30 roots were calculated and the analysis was performed by using both Differences of Transition Densities (DTD) and Natural Transition Orbitals (NTO). Finally, calculations of the ionic states were done by performing single point calculations on the ground-state geometry (i.e., in the vertical approximation). Whenever the Bond Dissociation Energies (DBE) were calculated, the same level of theory was used except for the choice of the basis set, for which a 6-31G** one was used for such calculations. These DBE calculations were performed in the adiabatic approximation (i.e., once broken apart, each fragment had its geometry optimized in the same level of theory).

\section{Notes and references}

1 H. Kang, G. Kim, J. Kim, S. Kwon, H. Kim, K. Lee, Adv. Mater., 2016, 28, 7821.

2 M. A. Green, K. Emery, Y. Hishikawa, W. Warta, E. D. Dunlop, Prog. Photovolt: Res. Appl., 2016, 24, 905.

3 G.E. Park, S. Choi, S. Y. Park, D. H. Lee, M. J. Cho, D. H. Cho Adv. Energy Mater., 2017, 7, 1700566.

4 C. Liu, K. Wang, X. Gong, A. J. Heeger, Chem. Soc. Rev., 2016, 45, 4825.

5 J. Zhang, L. Zhu, Z. Wei. Small Methods 2017, 1700258.

6 X. Che, Y. Li, Y. Qu, S. R. Forrest, Nature Energy, 2018, 3, 422.

7 A. J. Heeger, Chem. Soc. Rev., 2010, 39, 2354.

8 Z. He, C. Zhong, S. Su, M. Xu, H. Wu, Y. Cao, Nature Photonics, 2012, 6, 591.

9 L. Lu, L.Yu, Adv. Mater., 2014, 26, 4413.

10 B. Arredondo, M.B. Martín-López, B. Romero, R. Vergaz, P. Romero-Gomez, J. Martorell, Sol. Energy Mater. Sol. Cells, 2016, 144, 422.

11 H. J. Son, W. Wang, T. Xu, Y. Liang, Y. Wu, G. Li, L. Yu, J. Am. Chem. Soc., 2011, 133, 1885.

12 N. Y. Doumon, G. Wang, Ryan C. Chiechi, L. Jan Anton Koster, J. Mater. Chem. C, 2017, 5, 6611.

13 Z. Ding, J. Kettle, M. Horie, S. W. Chang, G. C. Smith, A. I. Shames, E. A. Katze, J. Mater. Chem. A, 2016, 4, 7274.

14 A. Tournebize, I. Fraga Domínguez, G. E Morse, C. TaviotGuého, A. Rivaton, H. Peisert, T. Chassé, Polym. Degrad. Stab., 2017, 146, 155.

15 S. Holliday, C. K. Luscombe, Adv. Electron. Mater., 2017, 1700416

16 A. Rivaton, A. Tournebize, J. Gaume, P.-O. Bussière, J.-L. Gardette, S. Therias, Polym. Inter., 2014, 63, 1335.

17 E. Darlatt, B. Muhsin, R. Roesch, C. Lupulescu, F. Roth, M. Kolbe, A. Gottwald, H. Hoppe, M. Richter, Nanotechnology, 2016, 27, 324005.

18 S. Shah, R. Biswas, J. Phys. Chem. C, 2015, 119, 20265.

19 J. Kettle, Z. Ding, M. Horie, G.C. Smith, Organic Electronics, 2016, 39, 222.

20 S. Alem, S. Wakim, J. Lu, G. Robertson, J. Ding, Y. Tao, Appl. Mater. Interfaces, 2012, 4, 2993.

21 J. Razzell-Hollis, J. Wade, W. C. Tsoi, Y. Soon, J. Durrant, J.-S. Kim, J. Mater. Chem. A, 2014, 2, 20189.

22 J. Kong, S. Song, M. Yoo, G.Y. Lee, O. Kwon, J.K. Park, H. Back, G. Kim, S.H. Lee, H. Suh, K. Lee, Nat. Commun., 2014, 5, 5688.

23 A. Perthué, T. Gorisse, H. Santos Silva, C. Lombard, D. Bégué, P. Hudhomme, B. Pépin-Donat, A. Rivaton, G. Wantz, Journal of Materials Research, 2018, 33(13), 1868.

24 W.R. Mateker, T. Heumueller, R. Cheacharoen, I.T. SachsQuintana, M.D. McGehee, J. Warnan, P.M. Beaujuge, X. Liu, G.C. Bazan, Chem. Mater., 2015, 27, 6345.

25 I. Fraga Dominguez, P. Topham, P.-O. Bussière, D. Bégué Didier, A. Rivaton, J. Phys. Chem. C, 2015, 119, 2166.

26 H. Santos Silva, I. Fraga Domínguez, A. Perthué, P. D. Topham, P.-O. Bussière, R. C. Hiorns, C. Lombard, A. Rivaton, D. Bégué, B. Pépin-Donat. J. Mater. Chem. A, 2016, 4, 15647.

27 M. Manceau, A. Rivaton, J.-L. Gardette, S. Guillerez, N Lemaître, Sol. Energy Mater. Sol. Cells, 2011, 95, 1315.

28 S. Chambon, A. Rivaton, J. L. Gardette, M. Firon, Sol.Energy Mater. Sol. Cells, 2008, 92, 785.

29 D. Lin-Vien, N.B. Colthup, W.G. Fateley, J.G. Grasselli. The Handbook of Infrared and Raman Characteristic Frequencies of Organic Molecules; Academic Press: San Diego, 1991. 
30 A. Tournebize, P.-O. Bussière, P. Wong-Wah-Chung, A.Rivaton, J.-L. Gardette, S. Beaupré, Mario Leclerc, Adv. Energy Mater., 2013, 3, 478 .

31 M. Manceau, S. Chambon, A. Rivaton, J.-L. Gardette, S. Guillerez, N Lemaître, Sol. Energy Mater. Sol. Cells, 2010, 94, 1572.

32 M. Manceau, A. Rivaton, J.L. Gardette, chap 4: Photochemical stability of materials for OPV. pp 71-108, in Stability and Degradation of Organic and Polymer Solar Cells, Ed. F.C. Krebs, Wiley Interscience, 2012.

33 A. Perthué, I. Fraga Domínguez, P. Verstappen, W. Maes, O. J. Dautel, G. Wantz, A. Rivaton, Sol. Energy Mater. Sol. Cells., 2018, 176, 336.

34 S. Chambon, M. Manceau, M. Firon, S. Cros, A. Rivaton, J. L. Gardette, Polymer, 2008, 49, 3288

35 H. H. Wasserman, D. L. Larsen, J. Chem. Soc. Chem. Commun., 1972, 253.

36 H. Hart, A. Oku, J. Chem. Soc. Chem. Commun., 1972, 254.

37 M. Manceau, A. Rivaton, J.-L. Gardette, S. Guillerez, N Lemaître, Polym. Degrad. Stab., 2009, 94, 898.

38 B. J. Tremolet de Villers, K. A. O'Hara, D. P. Ostrowski, P. H. Biddle, S. E. Shaheen, M. L. Chabinyc, D. C. Olson, N. Kopidakis, Chem. Mater., 2016, 28, 876.

39 A Tournebize, A. Rivaton, H. Peisert, T. Chassé. J. Phys. Chem. C, 2015, 119, 9142.

40 N. Y. Doumon, G. Wang, R. C. Chiechi, X. Qiu, A. J. Minnaard, L. J. A. Koster, Scientific Reports, 2019, 9, 4350.

41 E. T. Hoke, I. T. Sachs-Quintana, M. T. Lloyd, I. Kauvar, W. R. Mateker, A. M. Nardes, C. H. Peters, N. Kopidakis, M. D. McGehee, Adv.Energy Mater., 2012, 2, 1351.

42 M. Manceau, A. Rivaton and J.-L. Gardette, Macromol. Rapid Commun., 2008, 29, 1823.

43 M. Manceau, S. Chambon, A. Rivaton, J.-L. Gardette, S. Guillerez, N. Lemaître, Polym. Degrad. Stab. 2009, 94, 898.

44 J. Kong, S. Song, M. Yoo, G. Y. Lee, O. Kwon, J. K. Park, H. Back, G. Kim, S. H. Lee, H. Suh, K. Lee, Nat. Commun. 2014, 5, 1.

45 T. Vangerven, P. Verstappen, J. Drijkoningen, W. Dierckx, S. Himmelberger, A. Salleo, D. Vanderzande, W. Maes, J. V Manca, Chem. Mater. 2015, 27, 3726.

46 N.J. Turro, M.-F. Chow, J. Rigaudy, J. Am. Chem. Soc., 1981, 103, 7218.

47 J. Gaume, P. Wong-Wah-Chung, A. Rivaton, S. Therias, J.-L. Gardette, RSC Advances, 2011, 1, 1471. 